\title{
Art psychotherapy practice with adults who suffer from depression in the UK: Qualitative findings from a depression-specific...
}

Article in The Arts in Psychotherapy · October 2014

DOI: 10.1016/j.aip.2014.10.007

CITATION

1

3 authors:

\section{Ania Zubala}

University of Dundee

19 PUBLICATIONS 11 CITATIONS

SEE PROFILE

Vicky Karkou

Edge Hill University

49 PUBLICATIONS 148 CITATIONS

SEE PROFILE
READS

207

\section{Donald James Maclntyre}

The University of Edinburgh

54 PUBLICATIONS $\quad \mathbf{3 , 4 1 5}$ CITATIONS

SEE PROFILE

Some of the authors of this publication are also working on these related projects: 


\section{Accepted Manuscript}

Title: Art psychotherapy practice with adults suffering from depression in the UK: qualitative findings from depression-specific questionnaire

Author: Ania Zubala Donald J. MacIntyre Vicky Karkou

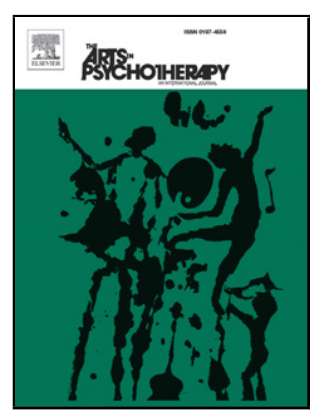

PII:

S0197-4556(14)00106-3

DOI: http://dx.doi.org/doi:10.1016/j.aip.2014.10.007

Reference: AIP 1282

To appear in: $\quad$ The Arts in Psychotherapy

Received date: $\quad 28-5-2014$

Revised date: 30-9-2014

Accepted date: $\quad 3-10-2014$

Please cite this article as: Zubala, A., MacIntyre, D. J., and Karkou, V.,Art psychotherapy practice with adults suffering from depression in the UK: qualitative findings from depression-specific questionnaire., The Arts in Psychotherapy (2014), http://dx.doi.org/10.1016/j.aip.2014.10.007

This is a PDF file of an unedited manuscript that has been accepted for publication. As a service to our customers we are providing this early version of the manuscript. The manuscript will undergo copyediting, typesetting, and review of the resulting proof before it is published in its final form. Please note that during the production process errors may be discovered which could affect the content, and all legal disclaimers that apply to the journal pertain. 


\section{Title Page}

Title

Art psychotherapy practice with adults suffering from depression in the UK: qualitative findings from depression-specific questionnaire.

Author names and affiliations

Ania Zubala, PhD a a.zubala@gmail.com; a.zubala@dundee.ac.uk (corresponding author) Donald J Maclntyre, MD ${ }^{\mathrm{b}}$ d.macintyre@ed.ac.uk

Vicky Karkou, PhD ${ }^{\mathrm{c}}$ karkouv@edgehill.ac.uk

a University of Dundee, College of Medicine, Dentistry and Nursing, Dundee, DD1 4HN, UK

b University of Edinburgh, Division of Psychiatry, Royal Edinburgh Hospital, Edinburgh, EH10 5HF, UK

${ }^{c}$ Edge Hill University, Faculty of Arts and Sciences, Ormskirk, L39 4QP, UK

Keywords

depression, art therapy, survey, UK, clinical practice, therapeutic process 
Title

\title{
Art psychotherapy practice with adults suffering from depression in the UK: qualitative findings from depression-specific questionnaire.
}

\begin{abstract}
The 'global burden' of depression demands more effective treatments. Evidence is available that arts therapies are offered to people suffering from depression. However, despite recently growing research, the ways of working and tools used by arts therapists still remain unclear. A nationwide survey among arts therapists was undertaken in 2011; practitioners who work primarily with depression were identified and invited to complete additional questionnaire focusing on specific aspects of their practice. Therapists responded offering detailed descriptions of their work with the condition. Data analysis led to findings which greatly enrich knowledge obtained from the main survey in areas concerning the meaning of depression and techniques/tools used by therapists. New insights into the work of arts therapists with depression additionally encompass therapeutic aims as well as challenges and rewards of the practice. The themes of motivation and time as well as the paradox of isolation versus the need to relate were identified by the respondents as crucial in the therapeutic process. The findings help understand the meaning and possibilities of arts therapies in the treatment of depression and the area would benefit from further in-depth research, particularly on techniques used by therapists and on the origins of therapeutic change. It is expected that this and future research will be of a special interest to arts therapists themselves and other professionals wishing to gain insight into what arts therapies practice with depression entails.
\end{abstract}




\section{Introduction}

In times where depression is steadily becoming the second most disabling illness in the world (WHO, 2010), exploration of available treatment options seems vital. In the UK, routinely offered treatments include antidepressant medication, psychosocial and psychological interventions. Combination of these is common (Sudak, 2011). However, currently recommended therapies (NICE clinical guideline 90, 2009; SIGN clinical guideline $114,2010)$ do not offer effective solutions for all depression sufferers - readmissions to mental health hospitals are common and the costs of the mental illness are rising (McCrone, Dhanasiri, Patel, Knapp \& Lawton-Smith, 2007).

Depression is a broad and heterogenous disorder (NICE guideline 90, 2009) with "different etiological and clinical features" (Hammen \& Watkins 2007: 36) or a "multifactorial illness with biological, social and psychological factors" (SIGN guideline 114, 2010) and thus, variety of types are recognized. Moreover, multiple theories of depression have been developed over the years, each highlighting one or several of its aspects, but usually failing to provide holistic perspective. For instance, cognitive issues in depression have been addressed by the cognitive-behavioural model, its genesis has been explained by the psychodynamic theorists (Abraham 2011), while its physical presentation is often tackled with prescribed exercise.

Referring to the biopsychosocial model of depression (O'Donohue \& Graybar, 2009), nowadays the need for holistic approach towards this condition is often stressed (LlewllynJones \& Donnelly, 2000) and a comprehensive treatment plan within interdisciplinary 
clinical teams is usually seen as the best way to achieve improvement in many aspects of life, affected by depression.

Arts therapies (art therapy, music therapy, dance movement therapy and dramatherapy), by recognising the value of creativity and non-verbal communication, may offer a suitable treatment option for some patients/clients. Although there is evidence that arts therapies are offered to clients experiencing depression, the scope and nature of these interventions remain unclear, which often impacts the credibility of evaluative studies.

Karkou and Sanderson (2006) offered a comprehensive general description of arts therapies practice in the UK, but did not focus on the specifics of working with depression. Although the literature includes accounts of arts therapists addressing depression (Dokter, 1996; Payne, 1996; Cattanach, 1999; Reynolds, Lim \& Prior, 2008), the available case studies often offer descriptions of individual practices, which do not form consistent patterns of the overall practice of arts therapies.

Question about the essence of therapy process, and about what aspects of practice lead to a desired change have been posed since the very beginnings of arts therapies and clearly hold clinical value for the practitioners (Maratos, Crawford \& Procter, 2011). Many authors mention and list therapeutic factors in arts therapies (e.g. Gersie, 1996 on dramatherapy, Schmais, 1985 on dance movement therapy). While the works often focus on foundations of psychotherapeutic interventions with added value of arts media and the role of artwork as significant object in therapy, they rarely mention tools or methods suited to particular client groups with varied needs, including depression.

A particularly relevant and valuable work in the area has recently been presented by Blomdahl, Gunnarsson, Guregård and Björklund (2013), who offer a unique description of art therapy practice with depression in a review of 16 relevant articles. While this work 
identifies therapeutic factors contributing to positive change in art therapy, no similar reviews were by far undertaken in other arts therapies and thus further description of practice remains unavailable. Among other developments, recent publications of results from the nationwide survey (Zubala, MacIntyre, Gleeson \& Karkou, 2013; Zubala, Maclntyre, Gleeson \& Karkou, 2014) added to the general picture of arts therapies practice with depression. However, more in-depth insights into the essence of therapeutic process are still required for a complete understanding of how arts therapies are applied in the treatment of depression and what exactly their practice involves.

\section{Aims of this research study}

The current paper presents additional qualitative findings of a descriptive phase of a larger research, which aimed to describe and evaluate arts therapies as interventions for addressing adult depression through the use of mixed methodologies. Description of how arts therapists work with people suffering from depression was the focus of the first phase of this project, gathering quantitative and qualitative data through the Arts Therapies Survey, of which results and findings were presented elsewhere (Zubala et al., 2013; Zubala et al., 2014). A depression-specific questionnaire followed the main Survey in order to increase the already created opportunities for gaining understanding of the nature of arts therapists' work with depression even further. The current report is based on detailed responses given by arts therapists who specialise in the treatment of depression and it offers answers to the following research questions:

- What is the meaning of depression for arts therapists who chose to target this condition in their practice? 
- What tools and interventions are commonly used by arts therapists in their work with depression?

- What are the challenges and rewards of arts therapies practice with people suffering from depression?

\section{Ethical approval}

This research received an ethical approval from Queen Margaret University, Edinburgh, in May 2011.

\section{Methodology}

In order to further our understanding of arts therapists' practice with depression, following the main survey (Arts Therapies Survey 2011) additional questionnaire with a series of open-ended questions was e-mailed to those participants, who worked specifically with depression and agreed to be contacted. The short questionnaire was designed by the principal author of this report to enable collection of more detailed accounts from those therapists who presumably had the most expertise and experience in working with adults with depression. The questions (Figure 1) were chosen to either further or complement the information received through the main survey. Among other questions, the participants were asked about their reason for being interested in working with people suffering from depression, challenges and rewards of this work and their views on which approaches and interventions they found particularly helpful in their work. 
[Figure 1 around here]

\section{Participants}

The additional depression-specific questionnaire was e-mailed to those arts therapists, who: 1) took part in the main survey, 2) worked primarily with depression and 3) agreed to be contacted for sharing further information about their practice. Out of the total of 395 respondents, 38 met the above criteria and were invited to complete an additional questionnaire.

The questionnaire was completed and returned by seven therapists, of whom five practised mainly art therapy or art psychotherapy. The remaining two participants reported to have used primarily: systemic psychotherapy and group analysis (both combined with art therapy). Thus, the additional findings may best describe art psychotherapy practice in particular and may be less accurate for other arts therapies disciplines.

\section{Data analysis}

The participants were offered an option to reply freely to the questions by providing as much detail as they felt appropriate and comfortable. Some of the respondents commented extensively while others offered answers less substantial in length but often nevertheless rich in content.

The process of analysis could most accurately be described by the method of template analysis, where a "template" is created, "which summarises themes identified by the researcher as important in a data set, and organises them in a meaningful and useful manner" (King, 2011). The template can originate "a priori" from theory and knowledge, or may emerge from the process of coding. An intermediate approach is common, where 
"some initial codes are refined and modified during the analysis process" (Crabtree \& Miller, 1999: 167).

In case of the current analysis most codes originated directly from the questions and were complemented by codes not initially expected, emerging from the responses.

Eventually, a template consisting of five categories, further listed, provided a frame for all findings.

\section{Findings}

Further report presents findings within the five categories classifying the content of arts therapists' responses. Whenever direct quotations are used, they are labelled with respondent's number only (e.g. T.3).

The first two categories are presented briefly, since they enhance previous findings from the Arts Therapies Survey 2011, but do not offer new insights to the subject examined. The further three categories present findings unique to the depression-specific questionnaire and are thus reported in more detail.

\section{Characteristics of clients}

"Variety" seems to be the one theme in arts therapists' comments on their main client group. According to respondents, it refers to co-morbidities often present alongside depression (e.g. schizophrenia, Bi-polar, psychosis, anxiety disorders, OCD, substance misuse, relational difficulties, attachment issues, medical problems), different social groups affected by depression (e.g. carers, refugees, people in isolation, parents) or referrals 
coming from various settings (e.g. multidisciplinary teams, mental health services, psychiatrists, GPs, social workers, self-referrals). Whenever therapists mentioned the average age of their clients, this was always labelled as 'adults' and fell between 18-65, with only one person mentioning working with adolescents alongside adults.

\section{Theoretical influences}

Asked to name their theoretical influences, the therapists again provided a variety of approaches, which could best be labelled with one of the respondents' expression - an "eclectic mix" (T.3). More specific backgrounds mentioned by the respondents included: psychodynamic, systemic, narrative, cognitive, humanistic, person-centred, solutionfocused, directive, intercultural, interpersonal, attachment theory, object relations, CBT and mentalization theories. One of the respondents stated that she/he successfully combined creative and cognitive techniques in her/his practice and said that "both approaches complement each other" (T.1).

\section{Meaning of depression}

The respondents were prompted to describe the meaning of depression for them, as therapists, and not necessarily reflecting commonly recognised clinical definitions. Statements which followed contained aspects of depression, considered generally known by mental health practitioners and widely mentioned in literature and clinical practice (e.g. psychological and biological symptoms: low mood, low self esteem, withdrawal, problems 
with sleep, etc.) as well as some less common expressions creatively reflecting the feeling of being depressed.

Interesting comments included physical presentation of depression and therapists mentioned that the movement is usually slowed and people affected "look down not around them when thinking" (T.4). Some of the aspects of depression which were mentioned seemed to be directly affecting the therapeutic process, especially when therapy was provided to a group. Such features included "inability to engage in meaningful activity" (T.3) (or even "avoidance of normal activity" T.5), "need to isolate" (T.7), "keep others away from this" (T.7) and feeling of being "trapped inside yourself" (T.1). One respondent similarly stated that a person is depressed when they "go into themselves" (T.4). All features of depression mentioned by the therapists are included in Figure 2.

[Figure 2 around here]

Encouraged by one of the questions, actual subjective and personal definitions of depression were also provided by the respondents. Some of the expressions used included: "a stuck place" (T.1), "a grey world" (T.1), "a habit of mind" (T.5) or "a personalised condition, (...) difficult to verbalise" (T.1). Depression was also referred to as "situation" (T.6) and "continuum" (T.2), presumably locating the condition outwith the person and suggesting its prolonging nature. One of the respondents' description read: "Emptiness, endlessness, oh no - not again - a sense of falling. Feeling that you'll be terrible company, toxic, need to isolate and keep others away from this" (T.7). These creative references to what it means to be depressed, seem to convincingly illustrate the mechanism of vicious cycle, the repeatedness and hopelessness of depression, together with the feelings of guilt and not being worth the attention of others. The designations of depression used by the respondents are presented in figure 3. 
[Figure 3 around here]

\section{Aims and interventions / tools}

Many of the therapists' responses concerned aims of therapy which they offered to adults suffering from depression. Specific tools and interventions were usually mentioned in the context of these aims. A comprehensive analysis of relations between these concepts revealed a matrix of ideas, which seemed to be successfully implemented by the therapists in their work with depression.

It became apparent that the interventions used by art therapists can be grouped into four main clusters of tools: artistic, verbal, group and time related. Some therapeutic aims seemed to be best addressed by tools belonging to certain categories, while others could be explored through the use of various techniques. Figure 4 visually illustrates those relationships.

[Figure 4 around here]

Arts-related tools were identified by the therapists as useful in the expression of problems and emotions and exploration of the meaning of depression. In addition, creativity offered a chance to look at problems or disturbing feelings from a perspective and often literally (e.g. "see the mood on paper" T.7). As one of the therapist stated, "working with images provides a concrete version of the condition thus beginning the process of recognising its power, exploring way to take control of [it]" (T.1). It was also mentioned that imagery and creativity might help in "positive generation of hopes and solutions" (T.5).

Verbal aspect of therapeutic intervention seemed to be valued by the therapists, who suggested that both expression and exploration of the problem may be enhanced by 
verbal communication. Specific techniques, coming from certain psychotherapeutic models, were mentioned, including circular questions (characteristic for systemic therapy) and externalising conversation (a concept derived from narrative therapy tradition).

Group work, and specifically working with themes chosen by the group, was also mentioned to be beneficial to those suffering from depression by "reducing isolation and encouraging sharing" (T.6).

Another set of interventions may be clustered around the theme of time. Some tools mentioned by the therapists make use of time to allow for a gained "perspective on how life has led to depression" T.3 (lifeline and genogram work) or visualisation of "the process of feelings and incidents" T.3 (comic strips). Looking more closely at issues around time during therapy seemed to bring realisation that depression is not eternal and may be fought ("to see times past and be able to realise that depression is something a person can survive" T.7).

One of the therapists mentioned intuition as a tool used in her/his practice (T.2) and, since the same concept also appeared in the statements from the main survey, it seemed important to include it in the matrix of interventions. Another therapist added that "realistic goals" (T.5) were crucial in setting up the therapeutic situation and, while not an intervention in itself, the observation that aims need to be achievable seems relevant to note.

\section{Challenges and rewards}

The respondents commented vastly on the challenges and rewards of working with depression. They generally felt that change in this client group was often difficult and 
sometimes impossible to achieve and clients' responsiveness to therapy was likely to be low (working with depression is "somewhat intractable" (T.2)). While possible, recovery from depression is a "slow process", where it is "hard to catch positive change" (T.7). Lack of internal personal resources and difficult life situations of the clients were mentioned as reasons for this challenge.

Another problem, which had already appeared in the previous findings (Zubala et al., 2014) seemed to be the lack of or low motivation and specific attitude among the long term depressed clients, who often did not believe that improvement was possible ("[client] believe they're just made that way" T.5). This may be a difficult point in which to start therapy and the solution, however not easy to implement, may be "imagining a place when patients were engaged and active, to start with hope, lending hope" (T.5). A lack of motivation to change and tendency to isolate themselves ("some people are isolated or isolating prior to therapy, may not be able to speak through feelings/mentalise until sufficient progress is made" (T.6)) leads clients to difficulties with turning up for sessions and responding to therapy.

Other challenges mentioned by the therapists included ineffective communication with other professionals ("not including me in the care plan meetings" (T.3)) and the way that clients were affected by medication. Two of the therapists also commented on the difficulties around the provision of psychotherapeutic treatment for depression, which, they felt, was not considered a priority in relation to other conditions. That, in consequence, led to a lack of significant evidence-based and systematic research. While this gap in research and only anecdotal evidence available should only mean that no obvious claims can be made that arts therapies are effective, it is "often taken to mean that there is evidence that they don't work" (T.3). Some interesting statements showed signs of professional 
frustration with policy makers not giving enough attention to the treatment and research in depression:

"I think that the 'depression' diagnosis tends to be lost amongst other diagnostic groups; it is often something that is ignored (ie therapy is not available under NHS) until it develops into something more acute. Offering more therapy for them [people affected by depression] could be a helpful preventative practice." (T.7)

"I think the reason there are no big research projects (like there have been for schizophrenia) is that people with depression are not seen as a danger - they are quiet and may harm themselves or commit suicide but are very unlikely to harm others (which a few people with schizophrenia do). It seems quite political to me!" (T.3)

The rewards of the therapeutic work with people who are depressed seemed to be a reverse of the challenges, at least to some extent. Four of seven therapists mentioned that change was often possible and they encountered their clients recovering ("often they do make progress" (T.3), "the best reward is to see it improve" (T.7)), regaining "better view of themselves" and enabled to "take charge of their lives" (T.1). One of the therapists highlighted the importance of appropriate "feedback about changes in patterns outside therapy" (T.6), as an indicator of a lasting change. Another respondent stated that clients suffering from depression could often assist in the making of good relapse prevention plans ("often people have great resources" (T.5)). However, one therapist added that a lift in mood often meant more challenges on the therapeutic journey to recovery ("when clients lift, it sometimes seems like a mourning process develops" (T.6)). The respondents seem to also draw professional satisfaction from clients simply turning up for sessions regularly ("means that they are getting something from it that they need" (T.4)). 


\section{Limitations}

Although the study as a whole collected a large amount of data through the main Arts Therapies Survey and accounts of particularly high quality through depression-specific questionnaire, the latter received only seven responses, coming mostly from art psychotherapists. Therefore, the themes of aims and tools used in therapy as well as challenges and rewards of practice may not necessarily be relevant to other arts therapies disciplines and should be interpreted with caution.

Moreover, collection of data through written accounts rather than interviews likely limited the number of respondents as well as the amount of information that arts therapists were willing to share. Future studies may wish to employ face-to-face interviews as a data collection method or gather responses through alternative communication channels suited to individual participants' preferences (phone, teleconferencing, etc.).

For the above reasons, the findings from the current depression-specific questionnaire should be seen as a pilot introduction rather than an exhaustive description of arts therapies practice with depression.

It also needs to be noted here that no definition of depression was given to the respondents and as such they were asked to interpret the meaning of depression freely. This means that the findings may relate to depression as a diagnosable illness but also to depressive psychological states or possibly to temporarily low mood. However, since a majority of respondents worked in healthcare settings, it may be assumed that they were used to referring to depression as a health condition. For the purpose of this project understanding what it meant to work with depression seemed more relevant than clarity on what specific concept the respondents were referring to. 


\section{Discussion}

The findings enriched previously presented results from the Arts Therapies Survey (Zubala et al., 2013; Zubala et al., 2014) by adding new depth to the points already raised and introducing new concepts to the discussion on how arts therapists work with depression. The core findings will now be discussed against the previous reports from the main survey and knowledge available from literature.

Firstly, the current findings support the previous finding that clients who suffer from depression do not form a homogeneous group and the diversity within it makes it extremely challenging to provide consistent definition, not to mention universal solutions. The respondents were clearly aware of common co-morbidities of depression (Kessler, Chiu, Demler \& Walters, 2005) and its prevalence within diverse social groups (Walsh, 2009).

The responses also support the notion from the main survey that arts therapists' practice with depression is often influenced by very different theoretical backgrounds and that most of arts therapists choose not to limit themselves to practising within a certain theoretical paradigm, but rather take from a variety of approaches and mix them accordingly to clients' needs and own preferences or skills. The current study, however, sheds more light on specific techniques considered by arts therapists especially relevant in the treatment of depression.

Examples included verbal interventions originating from systemic therapy (circular questions - Fleuridas, Nelson \& Rosenthal, 1986) and narrative therapy (externalising conversation - Stacey \& Hills, 2001). Mention of a specific technique of genogram, 
associated with solution-based (Kuehl, 1996) and family therapies (Jolly, Froom \& Rosen, 1980), indicated perceived appropriateness of incorporating tools supporting exploration of the issue of time during therapy. Similar motivation seemed to be associated with the use of comic strips, found, for example, in art therapy for autism (Epp, 2008). The concept of time appeared similarly important in the findings from the main survey and its significance for the therapy of depression seems apparent and may be worth exploring further.

Not surprisingly, the respondents readily commented on non-verbal qualities of arts therapies interventions and largely focused on the role of creativity in the therapeutic process. The same concept appears in the findings of Blomdahl, Gunnarsson, Guregård and Björklund (2014), who propose creativity as a crucial therapeutic factor in the treatment of depression. Recognition of the significance of creativity and artistic expression in arts therapies practice is common in the literature (e.g. Karkou \& Sanderson, 2006; Meekums, 2002). In the current study, focus on imagery and generally visual tools was apparent, which quite obviously reflects the particular arts therapy type practised by the majority of respondents. Should participants included arts therapists from other disciplines, other forms of artistic expression would most likely be mentioned.

An idea that group work might be especially relevant for those who suffer from depression seems to support quantitative results from the main survey, where arts therapists specialising in depression were more likely to offer group therapy than respondents who did not work with the condition (Zubala et al., 2013). The concept also relates to further qualitative findings (Zubala et al., 2014), where the need for reconnecting was considered an important factor in the therapeutic process.

Interestingly, although not directly prompted by questions, the aims of therapy were largely commented on by the respondents, especially in connection with specific 
therapeutic tools. Karkou and Sanderson (2006) notice that specific client needs determine selection of therapeutic aims and it may be assumed that particular needs of people suffering from depression would call for specific aims. In the current study, some of the mentioned aims were more general and applicable to many therapeutic situations (e.g. to express feelings, to generate hope), while others seemed to directly tackle underlying issues in depression (e.g. to explore meaning behind depression, to realise that depression may be survived). According to Liebmann's (1981) classification, the listed aims may also be considered 'social' (e.g. to encourage sharing) or 'personal' (e.g. to generate hope). Some of the above aims resonate with the findings of Blomdahl et al. (2014), who identified selfexpression, self-exploration, communication and understanding among the therapeutic factors in art therapy for depression. More research into what constitutes aims of arts therapies for the condition is highly recommended and could potentially aid understanding of those therapies' unique potential.

Despite highlighting commonly observed features of depression, definitions offered by the respondents are rarely how the condition is described in medical context. By welcoming informal unrestricted language and the use of metaphors the current study brought insight into how arts therapists understand depression, which must inevitably have consequences in their therapeutic approaches. These comments seem to well illustrate one of the paradoxes of depression: the need to relate and engage versus the avoidance of others and the tendency to isolate.

Furthermore, the therapists' comments seem to support the finding from the main survey and from the recent literature (McBride, Zuroff, Ravitz, Koestner, Moskowitz, Quilty \& Bagby, 2010; Smith, 2013) that depression appears to be closely linked to motivation, the lack of which often becomes one of the most challenging aspects of the condition, 
manifesting in therapy as an inability to engage. Helping the client to get out of the "stuckness", to break the vicious cycle of disengagement and isolation, to accept support and to open for others around may present one of the most significant aims in therapy of depressed adults and arts therapies, especially in groups, may provide useful tools. While creativity promotes openness, it encourages sharing and helps to accept the presence of other people in the process of recovery. One of the therapists mentioned that the "symptomatic imagery often comes in the form of black shapes, spaces and dread" (T.5). Metaphorically and literally, creativity could promote the introduction of 'colour' in one's life.

It should be stressed that the aims and tools mentioned in the current report do not by any means constitute a comprehensive or exhaustive list as resulted solely from the responses of seven art therapists. The list is not intended for use on its own, but could rather be considered a part of a bigger picture, which should include available clinical literature and data from other studies. Nonetheless, this is a rare collection of techniques coming directly from therapists who work with depression and has already been used as a guide for creation of a treatment manual utilised in a study to be reported on in a separate publication.

\section{Conclusions}

The findings from the current study, as expected, provided more depth into the previously reported results and explored areas, which could not be addressed through the use of numbers purely. Seven arts therapists completed the specifically qualitative survey, offering detailed and insightful comments on their practice with depression. This way, 
additional information about the practitioners and their clients became available, which helps to imagine what the encounter of a therapist and a depression sufferer may look like. The realisation of the nature of the therapeutic process, in addition, helps to understand how this relationship may and should develop in order to bring benefit to the client and professional satisfaction to the therapist.

Generally, in order to address complex needs of depression sufferers, therapists felt that it was most appropriate to employ an "eclectic mix" of approaches and techniques, which perhaps highlight the ambiguity of the disorder. It was recognised that, while verbal communication, not dissimilar to other psychotherapies, has an important role in therapy, creative expression and communication through arts media added a valuable dimension to the process and might be especially beneficial to clients with depression by helping them to reconnect to others and feelings, express emotions and generate new hopes and meaning. In light of this finding, health services employing arts therapists may wish to acknowledge the flexibility which the therapists need in order to offer best treatment for depression.

While depression is a complex condition, not easy to define and interconnected to other mental and physical disorders, it seems to present specific challenges in therapy, where the issue of motivation and time as well as the paradox of isolation versus the need to relate became apparent and main themes within the therapeutic process, as described by the respondents. Arts therapists' work with depression seems to be both demanding and rewarding, when the client experiences the benefits of therapy and moves from "turning inwards" to reconnection and re-discovered meaning.

Further research into the nature of the therapeutic process in arts therapies with depression is highly recommended. Understanding of the aims and tools through which the treatment is facilitated would enable further exploration of the unique potential of arts 
therapies in addressing depression in evaluative studies. Most importantly, even more insights into what exactly happens in the therapy and how aims are achieved would be of a great clinical value and empower current arts therapies practice with depression.

\section{Acknowledgements}

Ania Zubala would like to thank all arts therapists, who took part in the survey, and especially those, who shared insights into their practice with depression. She would also like to express gratitude to Queen Margaret University for awarding her with a PhD bursary to research arts therapies.

\section{References}

Abraham, K. (2011). Selected Papers on Psychoanalysis. London: Karnac Books.

Blomdahl, C., Gunnarsson, A. B., Guregård, S. \& Björklund, A. (2013). A realist review of art therapy for clients with depression, The Arts in Psychotherapy, 40(3), 322-330. doi:10.1016/j.aip.2013.05.009.

Cattanach, A. (1999). Process in the arts therapies. London: Jessica Kingsley Publishers.

Crabtree, B. F. \& Miller, W. L. (1999). Doing qualitative research. Thousand Oaks, Calif.: Sage Publications.

Dokter, D. (1996). Being together briefly: One-on-one brief dramatherapy with clients hospitalized for chronic or reactive depression, In: Gersie A. (ed.) Dramatic approaches to brief therapy. London: Jessica Kingsley Publishers, 188-200.

Epp, K. M. (2008). Outcome-Based Evaluation of a Social Skills Program Using Art Therapy and Group Therapy for Children on the Autism Spectrum. Children \& Schools, 30(1). 27-36. doi:10.1093/cs/30.1.27. 
Fleuridas, C., Nelson, T. S., \& Rosenthal, D. M. (1986). The Evolution Of Circular Questions: Training Family Therapists. Journal of Marital and Family Therapy, 12(2), 113-127. doi:10.1111/j.1752-0606.1986.tb01629.x.

Gersie, A. (1996). Dramatic Approaches to Brief Therapy. Jessica Kingsley Publishers.

Jolly, W., Froom, J., \& Rosen, M. (1980). The genogram. The Journal of Family Practice, 10(2), 251-255.

Karkou, V. \& Sanderson, P. (2006). Arts Therapies: A Research-based Map of the Field. London: Churchill Livingstone.

Kessler, R. C., Chiu, W., Demler, O. \& Walters E. E. (2005). Prevalence, severity, and comorbidity of 12-month DSM-IV disorders in the national comorbidity survey replication, Archives of General Psychiatry, 62(6), 617-627. doi:10.1001/archpsyc.62.6.617.

King N. (2011). Template analysis. Retrieved from: http://www2.hud.ac.uk/hhs/ research/template_analysis/index.htm.

Kuehl, B. R. (1996). The Use of Genograms with SolutionBased and Narrative Therapies. The Family Journal, 4(1), 5-11. doi:10.1177/1066480796041002.

Liebmann, M. (1981). The many purposes of art therapy. Inscape, 5(1), 26-28.

Llewllyn-Jones, S. \& Donnelly, P. (2000). Diagnosing and treating depression: A holistic approach is recommended, BMJ, 320(7249), 1602. doi:10.1136/bmj.320.7249.1602.

Maratos, A., Crawford, M. J., \& Procter, S. (2011). Music therapy for depression: it seems to work, but how? The British Journal Of Psychiatry: The Journal Of Mental Science, 199(2), 92-93. doi:10.1192/bjp.bp.110.087494.

McBride, C., Zuroff, D. C., Ravitz, P., Koestner, R., Moskowitz, D. S., Quilty, L., \& Bagby, R. (2010). Autonomous and controlled motivation and interpersonal therapy for depression: Moderating role of recurrent depression. British Journal Of Clinical Psychology, 49(4), 529-545. doi:10.1348/014466509X479186.

McCrone, P., Dhanasiri, S., Patel, A., Knapp, M. \& Lawton-Smith, S. (2007). Paying the price. The cost of mental health care in England to 2026. London: King's Fund.

Meekums, B. (2002). Dance movement therapy a creative psychotherapeutic approach. Thousand Oaks, CA: Sage Publications.

National Institute for Health and Clinical Excelence (2009). Depression. The treatment and management of depression in adults. NICE clinical guideline 90. National Collaborating Centre for Mental Health. 
O'Donohue, W. \& Graybar S. R. (2009). Handbook of Contemporary Psychotherapy: Toward an Improved Understanding of Effective Psychotherapy. Thousand Oaks: Sage.

Payne, H. (1996). One river many currents: Handbook of inquiry in the arts therapies. London: Jessica Kingsley Publishers.

Reynolds, F., Lim, K. \& Prior, S. (2008). Narratives of therapeutic art-making in the context of marital breakdown: older women reflect on a significant mid-life experience, Counselling Psychology Quarterly, 21(3), 203-214.

Schmais, C. (1985). Healing processes in group dance therapy, American Journal of Dance Therapy, 8(1), p. 17.

Scottish Intercollegiate Guidelines Network (2010). 114. Non-pharmaceutical management of depression in adults. A national clinical guideline. NHS Quality Improvement Scotland.

Smith, B. (2013). Depression and motivation. Phenomenology And The Cognitive Sciences, 12(4), 615-635. doi:10.1007/s11097-012-9264-0.

Stacey, K., \& Hills, D. (2001). More Than Protest: Further Explorations of Alternative Metaphors in Narrative Therapy. Australian \& New Zealand Journal of Family Therapy, 22(3), 120-128.

Sudak, D. M. (2011). Combining CBT and Medication: An Evidence-Based Approach. New Jersey: John Wiley \& Sons.

Walsh, L. (2009). Depression care across the lifespan. Chichester: Wiley-Blackwell.

World Health Organization (2010). Depression. Retrieved from: http://www.who.int/ mental_health/management/depression/definition/en/.

Zubala, A., Maclntyre, D. J., Gleeson, N. \& Karkou, V. (2014, forthcoming). Description of arts therapies practice with adults suffering from depression in the UK: Qualitative findings from the nationwide survey, The Arts in Psychotherapy.

Zubala, A., MacIntyre, D. J., Gleeson, N. \& Karkou, V. (2013). Description of arts therapies practice with adults suffering from depression in the UK: Quantitative results from the nationwide survey, The Arts in Psychotherapy, 40(5), 458-464.

doi:10.1016/j.aip.2013.09.003. 


\section{Figures}

Figure 1: Depression-specific questionnaire.

Figure 2: Symptoms of depression mentioned by the respondents.

Figure 3: Arts therapists' responses to the question: 'What does depression mean to you as therapist?'

Figure 4: Aims and tools identified by arts therapists, who work primarily with depression, as helpful in their practice. 


\section{Your practice with clients/patients with depression}

(questions following the Arts Therapies Survey 2011)

Please answer these questions honestly and sharing as much or as little details

as you find comfortable and/or appropriate.

- What is the main therapy type you are using in your practice?

- Why do you work with people suffering from depression? (eg. personal interest, motivation; nature/requirement of work setting)

- What are the main characteristics of your clients / patients other than depression? (eg. age groups, other prevailing conditions, referral procedures)

- Are there any specific theoretical influences which you find especially useful in your work with people with depression? If so, what are they?

- Are there any specific interventions and/or tools which you find most helpful and use most often in your practice? If so, what are they?

- What does depression mean to you as a therapist? How would you define / describe this condition based on your experience?

- Do you encounter any specific challenges while working with people with depression? If so, what are they?

- Do you experience any particular rewards from working with people with depression? If so, what are they?

- Would you like to make any further comments on your practice with people who suffer from depression?

Figure 1: Depression-specific questionnaire. 


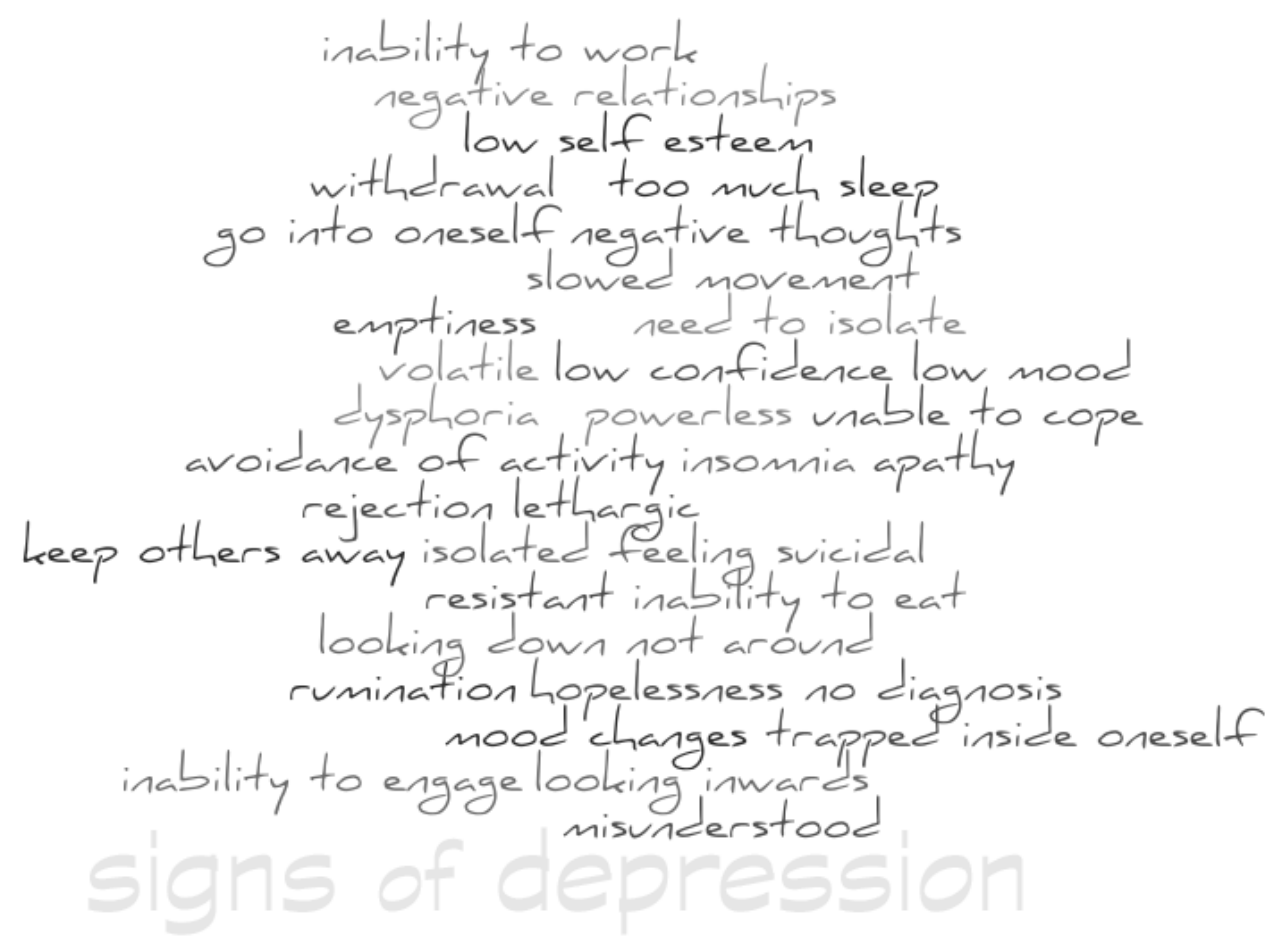

Figure 2: Symptoms of depression mentioned by the respondents. 


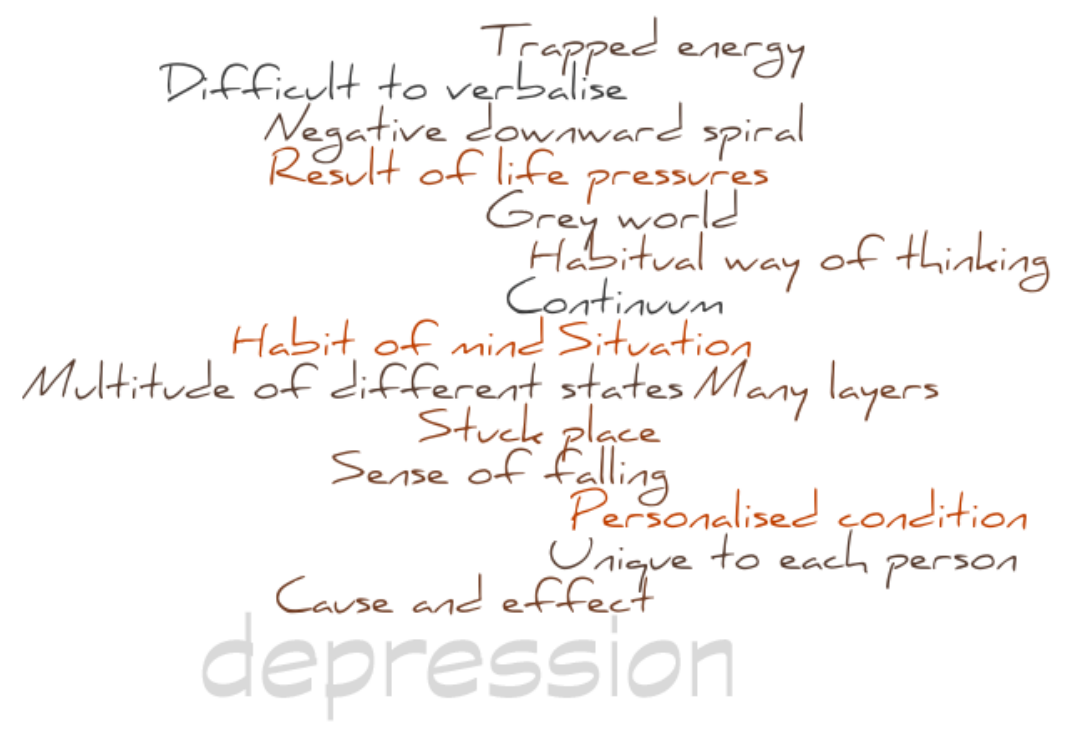

Figure 3: Arts therapists' responses to the question: 'What does depression mean to you as therapist?' 


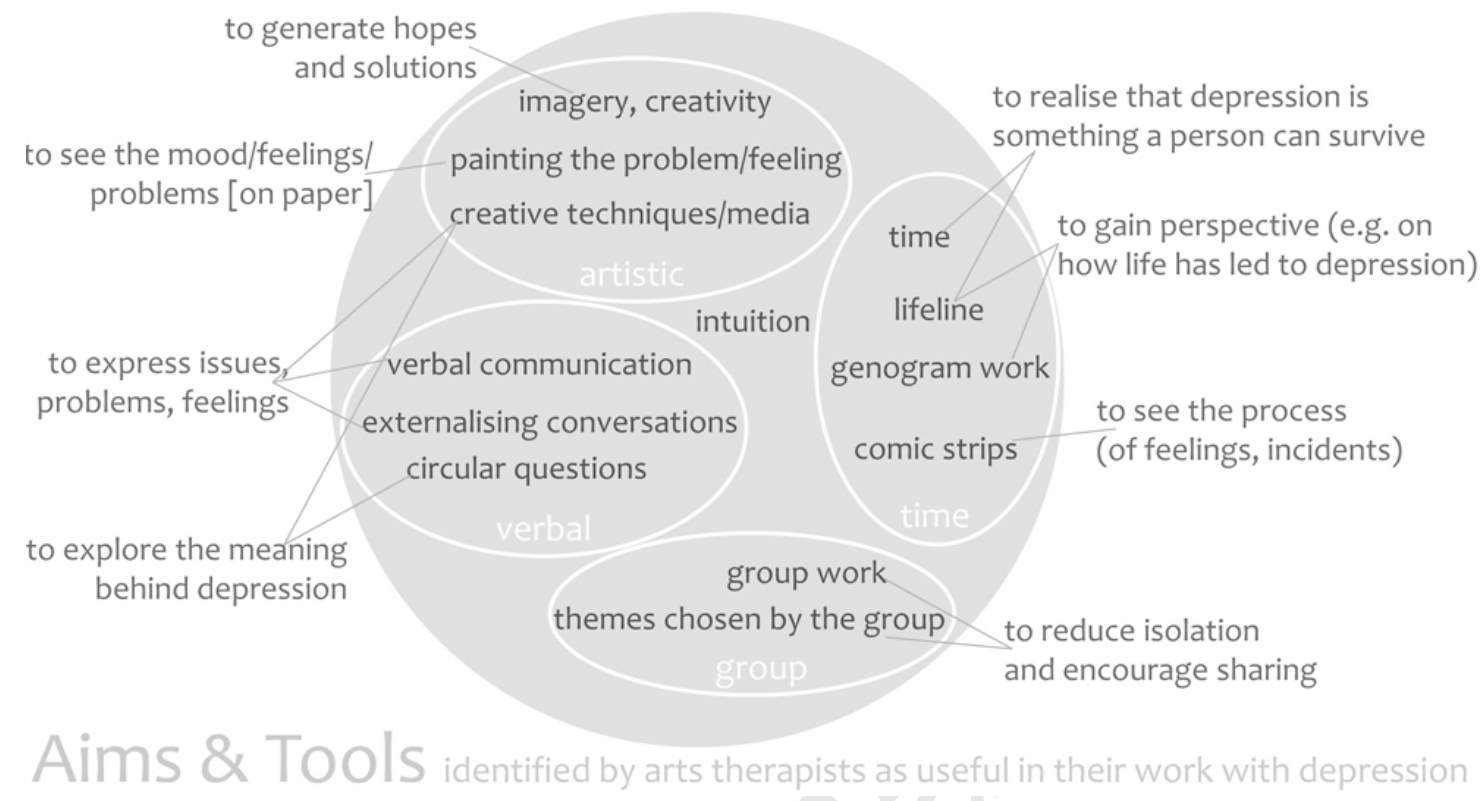

Figure 4: Aims and tools identified by arts therapists, who work primarily with depression, as helpful in their practice. 


\section{Highlights}

- Arts therapists who specialize in working with depression were identified through Arts Therapies Survey 2011

- Qualifying therapists were invited to complete detailed depression-specific questionnaire

- Responses from seven therapists added depth to data collected in the main Survey

- New insights encompass tools used by practitioners, aims of therapy and challenges and rewards of the practice 